\title{
Vertical transmission of maternal COVID-19 antibodies after CoronaVac vaccine: A case report
}

\author{
Bruno Thizon Menegali ${ }^{[1],[2],}$ Fabiana Schuelter-Trevisol[1],[2], Alexandre Naime Barbosa ${ }^{[3]}$, \\ Talita Menegali Izidoro ${ }^{[2]}$, Otto Henrique May Feurschuette ${ }^{[2]}$, \\ Chaiana Esmeraldino Mendes Marcon ${ }^{[1],[2]}$ and Daisson José Treviso[[1],[2]
}

\author{
[1]. Universidade do Sul de Santa Catarina, Programa de Pós-Graduação em Ciências da Saúde, Tubarão, SC, Brasil. \\ [2]. Universidade do Sul de Santa Catarina, Faculdade de Medicina, Tubarão, SC, Brasil. \\ [3]. Universidade do Estado de São Paulo, Departamento de Doenças Infecciosas, Botucatu, SP, Brasil.
}

\begin{abstract}
The use of coronavirus disease 2019 RNA vaccines in pregnant women led to reports on the first cases of newborns with antibodies to sudden acute respiratory syndrome coronavirus 2 (SARS-CoV-2), a phenomenon that was unknown when using immunizations with inactivated viruses. Thus, this study aimed to report a case of passive anti-SARS-CoV-2 immunity in a newborn through immunoprophylaxis of a pregnant woman who received the CoronaVac ${ }^{\circledR}$ vaccine in the third trimester of pregnancy. Twenty-four hours after delivery, samples were collected from the newborn and screened by enzyme immunoassays, which revealed antibodies to SARS-CoV-2.
\end{abstract}

Keywords: Coronavirus infections. Immunization passive. Vaccine.

\section{INTRODUCTION}

The novel coronavirus disease (COVID-19) is an extremely contagious respiratory transmissible disease caused by severe acute respiratory syndrome coronavirus 2 (SARS-CoV-2), which in adults may lead to severe viral pneumonia requiring hospitalization in about $10-15 \%$ of infected patients and a general lethality rate of $2-3 \%^{1}$. Pregnant and postpartum women are more vulnerable to severe COVID-19 infections than their non-pregnant counterparts with the same baseline characteristics ${ }^{1,2}$.

The effects of COVID-19 on pregnant women and their babies are still being studied. Pregnancy alters various functions of the human body, leaving women more vulnerable to infectious diseases, including SARS-CoV-2 and its vertical transmission to the fetus; the latter has not yet been ruled out ${ }^{3}$.

SARS-CoV-2 infections present a very heterogeneous clinical scenario that may depend on the viral load and vulnerability of an infected person. Symptoms may include cough, runny nose,

\footnotetext{
Corresponding author: M.Sc. Bruno Thizon Menegali.

e-mail: prof.brunotm@gmail.com

(i) https://orcid.org/0000-0001-7347-159X

Received 1 July 2021

Accepted 3 September 2021
}

fever, sore throat, and dyspnea that can vary from asymptomatic to severe respiratory failure ${ }^{4}$. Although elderly people and adults with comorbidities are the most vulnerable group for aggravation and death, pregnant women and infants aged $0-1$ year are also vulnerable to COVID-19 complications ${ }^{2,5}$.

There are limited data regarding the safety of vaccines against COVID-19 during pregnancy. Clinical trials on their efficacy and safety did not include pregnant women; therefore, the decision to vaccinate pregnant women against COVID-19 is based on a risk-benefit ratio. In Brazil, pregnant healthcare professionals working on the frontline of the COVID-19 outbreak were immunized with CoronaVac ${ }^{\circledR}$ because this vaccine uses a known and safe technology for pregnancy as long as its use is recommended by a woman's obstetrician'.

This study aimed to report a case of passive transmission of anti-SARS-CoV-2 antibodies through immunoprophylaxis in pregnant women during the third trimester of pregnancy.

\section{CASE REPORT}

T.M.I, a 33-year-old physician, was multiparous. On February 23, 2021, at 34 weeks of gestation, she received the first $0.5 \mathrm{~mL}$ dose of the CoronaVac ${ }^{\circledR}$ vaccine (Instituto Butantan, São Paulo, Brazil) containing $600 \mathrm{SU}$ of the inactivated virus antigen to SARS-CoV-2. A second dose of equal volume and composition 
was administered on March 15, 2021, when she was at 37 weeks of gestation. No complications were detected during prenatal care. She attended 10 antenatal consultations without any symptoms of SARS-CoV-2 infection. There was a weight gain of $14 \mathrm{~kg}$, and she ended the pregnancy at a weight of $110 \mathrm{~kg}$ and height of $166 \mathrm{~cm}$.

The delivery took place at 39 weeks of gestation by cesarean section on April 9, 2021. The newborn was male, weighed $3.44 \mathrm{~kg}$, was $48 \mathrm{~cm}$ long, and had a head circumference of $33 \mathrm{~cm}$. He was breastfed, and a comprehensive physical assessment revealed that he was healthy. The Apgar scores at 1 and 5 minutes were 9 and 10 , respectively.

Blood specimens were collected by peripheral venipuncture $24 \mathrm{~h}$ after birth to detect neutralizing antibodies against SARSCoV-2/COVID-19. The serological test, carried out by enzymatic immunoassay (cPass ${ }^{\mathrm{TM}}$ SARS-CoV-2 Neutralization Antibody Detection Kit, GenScript, Make Research Easy), showed a result of $22 \%$, which was considered positive based on the cutoff value of $20 \%$. The cPass ${ }^{\mathrm{TM}}$ SARS-CoV-2 Neutralization Antibody Detection Kit is a blocking enzyme-linked immunosorbent assay (ELISA) intended for the qualitative direct detection of total neutralizing antibodies to SARS-CoV-2 in human serum and K2-EDTA plasma as a detection tool. Using purified receptor binding domain, protein from the viral spike (S) protein, and the host cell receptor ACE2, this test is designed to mimic the virus-host interaction by a direct protein-protein interaction in a test tube or a well of an ELISA plate. This highly specific interaction can then be neutralized in the same manner as in a conventional virus neutralization test.

This study was approved by the Research Ethics Committee of the University of Southern Santa Catarina (opinion no. 4.728.687) on May 24, 2021. Informed consent was obtained from the mother of the child prior to the data collection.

\section{DISCUSSION}

The inactivated SARS-CoV-2 vaccine with aluminum hydroxide developed by Sinovac Life Sciences Co. Ltd., known as CoronaVac ${ }^{\circledR}$, has been shown to be safe and effective for inducing neutralizing specific antibodies?

The Butantan Institute (Brazil) conducted a study of 9,823 participants who received two doses of CoronaVac between July and December 2020. The primary efficacy rate was $50.7 \%$ (95\% confidence interval [CI], 36.0-62.0) against symptomatic COVID-19, while the secondary efficacy was $83.7 \%$ (95\% CI, 58.0-93.7) against moderate cases requiring assistance and $100 \%$ (95\% CI, 56.4-100.0) against severe cases ${ }^{7}$.

In this case report, the CoronaVac vaccine was administered to a pregnant woman and assumed to be safe according to the literature because inactivated vaccines consist of dead antigens and are safe for this specific group without any major adverse effects or damage to the fetus. Studies have revealed that the vaccination of pregnant women against influenza, hepatitis A, and tetanus, for example, is common practice ${ }^{6,8}$.

Studies comparing the behavior of COVID-19 between pregnant and non-pregnant women have been conducted to enhance antenatal care and find safe alternatives to immunization during pregnancy. These studies showed that pregnant women who acquired SARS-CoV-2 and developed infectious symptoms were at great risk of hospital admission; the development of severe conditions requiring intensive care unit admission; progression to respiratory failure requiring invasive ventilation (endotracheal intubation); and, consequently, a high mortality risk. From an obstetric point of view, high rates of preterm births and the prevalence of operative deliveries have been observed as wel12,5.

In this case report, passive immunity may have occurred via the transplacental route measured by total antibodies after exposure to inactivated antigens of the vaccine administered in the third gestational trimester. Immunoglobulin $\mathrm{G}$ transfer from the mother to the fetus begins at the end of the first trimester of gestation and increases throughout pregnancy, ranging from $10 \%$ of maternal concentration in weeks $17-22$ to $50 \%$ in weeks $28-32$. The concentration continues to increase in the third trimester, allowing fetal antibody concentrations to exceed maternal levels by $20-30 \% 9$. Studies suggest that the detection of immunoglobulin $\mathrm{M}$ in umbilical cord blood is more common in women who are vaccinated in the second or third trimester of pregnancy as already evidenced in studies of the vaccines for tetanus and influenza ${ }^{8,9,10}$.

Therefore, immunization during pregnancy can increase maternal immune protection and provoke the production and transfer of antibodies across the placenta to provide early infant protection. Recent studies have shown that this strategy is a safe and efficient means for protecting mothers and infants from vaccinepreventable infections ${ }^{11}$.

Vaccination during pregnancy is a strategy to improve the health of mothers, fetuses, and newborns. Understanding the characteristics of antibody transfer is crucial to the development of a vaccine to help protect newborns ${ }^{12}$. However, it is important to conduct longitudinal studies on the duration of immunity for both mothers and children as well as the need for a third dose or vaccine booster. Children under 12 years of age are currently not covered by the National Immunization Plan against COVID-19 in Brazil.

In this case report, passive immunity to the fetus was observed through maternal vaccination. The mother was exposed to inactive virus, a technology used in the CoronaVac ${ }^{\circledR}$ immunizer. The two doses administered at 31 and 34 weeks of gestation provided an increase in the mother's total antibodies and, consequently, provided immunity to the fetus as assessed by the total antibody response.

To the best of our knowledge, this is the first case of newborn immunization after vaccination of the mother during the third trimester of pregnancy with the CoronaVac ${ }^{\circledR}$ vaccine. The monitoring of this and similar cases is essential to estimating the duration of circulating antibodies in the child and the role of breastfeeding in maintaining immunity against SARS-CoV-2.

\section{ACKNOWLEDGMENTS}

The present research was supported by the research team of Postgraduate Program in Health Sciences of the University of Southern Santa Catarina. 


\section{FINANCIAL SUPPORT}

University of Southern Santa Catarina.

\section{AUTHOR' CONTRIBUTION}

BTM and FST conceived of the presented idea and developed the theory. ANB verified the methods and theory. TMI and OHMF carried out the experiment. CEMM helped supervise the project. DJT supervise the project. All authors discussed the results and contributed to the final manuscript.

\section{ORCID}

Bruno Thizon Menegali: 0000-0001-7347-159X

Fabiana Schuelter-Trevisol: 0000-0003-0997-1594

Alexandre Naime Barbosa: 0000-0002-2187-4722

Talita Menegali Izidoro: 0000-0003-2246-9566

Otto Henrique May Feurschuette: 0000-0001-7908-7708

Chaiana Esmeraldino Mendes Marcon: 0000-0001-7031-437X

Daisson José Trevisol: 0000-0002-7053-9082

\section{REFERENCES}

1. Zambrano LD, Ellington S, Strid P, Galang RR, Oduyebo T, Tong VT, et al. Update: Characteristics of Symptomatic Women of Reproductive Age with Laboratory-Confirmed SARS-CoV-2 Infection by Pregnancy Status. MMWR Morb Mortal Wkly Rep. 2020;69(44):1641-7.

2. Allotey J, Stallings E, Bonet M, Yap M, Chatterjee S, Kew T, Debenham $\mathrm{L}$, et al. Clinical manifestations, risk factors, and maternal and perinatal outcomes of coronavirus disease 2019 in pregnancy: living systematic review and meta-analysis. BMJ. 2020;1:370:3320. Available from: https://doi.org/10.1136/bmj.m3320
3. Wastnedge EAN, Reynold RM, van Becker SR, Stock SJ. Denison FC, Maybin JA, et al. Pregnancy and COVID-19. Physiol Rev. 2020;101(1):303-18.

4. Iser BPM, Silva I, Raymundo VT, Poleto MB, Schuelter-Trevisol F, Bobinski F. Suspected COVID-19 case definition: a narrative review of the most frequent signs and symptoms among confirmed cases. Epidemiol Serv Saude. 2020;29(3):202-33.

5. Nakamura-Pereira M, Andreucci CB, Menezes MO, Knobel R, Takemoto MLS. Worldwide maternal deaths due to COVID-19: A brief review. Int J Gynaecol Obstet. 2020;151(1):148-50.

6. Quintana SM. We have Vaccine for COVID-19! What to Recommend for Pregnant Women? Rev Bras Ginecol Obstet. 2021;43(2):81-3.

7. Palacios R, Patiño EG, Piorelli RO, Conde MTRP, Batista AP, Zeng G, et al. Double-Blind, Randomized, Placebo-Controlled Phase III Clinical Trial to Evaluate the Efficacy and Safety of treating Healthcare Professionals with the Adsorbed COVID-19 (Inactivated) Vaccine Manufactured by Sinovac - PROFISCOV: A structured summary of a study protocol for a randomised controlled trial. Trials. 2020;15;21(1):853. Available from: https://doi.org/10.1186/s13063-020-04775-4.

8. Englund JA, Mbawuike IN, Hammil H, Holleman MC, Baxter BD, Glezen WP. Maternal immunization with influenza or tetanus toxoid vaccine for passive antibody protection in young infants. J Infect Dis.1993;168(3):647-56.

9. Breslin N, Baptiste C, Gyamfi-Bannerman C, Miller R, Martinez $\mathrm{R}$, Berstein K, et al. Coronavirus disease 2019 infection among asymptomatic and symptomatic pregnant women: two weeks of confirmed presentations to an affiliated pair of New York City hospitals. Am J Obstet Gynecol MFM. 2020;2(2):100-18.

10. Rastogi D, Wang C, Mao X, Lendor C, Rothman PB, Miller RL. Antigen-specific immune responses to influenza vaccine in utero. J Clin Invest. 2007;117(6):1637-46.

11. Poehling KA, Szilagyi PG, Staat MA, Snively BM, Payne DC, Bridges $\mathrm{CB}$, et al. Impact of maternal immunization on influenza hospitalizations in infants. Am J Reprod Immunol. 2011;204(6):141-8.

12. Toner LE, Gelber SE, Pena JA, Fox NS, Rebarber A. A Case Report to Assess Passive Immunity in a COVID Positive Pregnant Patient. Am J Perinatol. 2020;37(12):1280-2. 